\title{
A LEITURA E A (RE) ESCRITA DA HISTÓRIA DOS CIENTISTAS PELOS ESTUDANTES DO ENSINO MÉDIO
}

\author{
Reading and the (re) writing of the history of scientists by students of middle school \\ La lectura y la (re) escrita de la historia de los científicos por los estudiantes de la \\ educación secundaria
}

\author{
Renan Vilela Bertolin ${ }^{1}$ \\ Andreia Francisco Afonso ${ }^{2}$
}

\begin{abstract}
Resumo
Os exercícios de leitura e escrita são indispensáveis à formação humana, uma vez que por meio deles somos capazes de nos expressar e dialogar. Logo, é importante e necessário o desenvolvimento de práticas de leitura e escrita em aulas de ensino médio de todas as disciplinas. Nesse contexto, esse trabalho apresenta uma intervenção didática nessa perspectiva, a de produção de diários de cientistas, por meio do exercício da escrita criativa em turmas do segundo ano do ensino médio em aulas de Química. Por meio do estudo dos diários através da Análise de Conteúdo, foi possível verificar possíveis aproximações com as realidades vivenciadas pelos estudantes, uma vez que foram transferidas para os cientistas ações, medos e vivências características tanto da idade como do contexto social.
\end{abstract}

PALAVRAS-CHAVE: Escrita criativa. Realidades sociais. Ensino de Química.

\begin{abstract}
Reading and writing are indispensable to human formation, because through them we are able to express and dialogue. Therefore, it is important and necessary to develop reading and writing practices in high school classes. In this context, we present a didactic intervention about the production of scientists' diaries, through the exercise of creative writing in the sophomore Chemistry classes. We analyze the diaries through Content Analysis, thus it was possible to verify approximations with the realities experienced by the students in their daily life, once they were transferred to the scientists' actions, fears, experiences characteristic of both the age and the social context.
\end{abstract}

KEYWORDS: Creative writing, Social reality, Chemistry Teaching.

\section{Resumen}

\footnotetext{
${ }^{1}$ Licenciando em Química. Professor de Educação Básica I - Química. Escola Estadual Prof. Gabriel Félix do Amaral, Endereço: Av. José Pereira Lopes, 1871 - Jardim Botafogo, São Carlos/SP. CEP: 13.575-380 Telefone: (16) 3372-1191. Email: renanvile@ hotmail.com

${ }^{2}$ Doutora em Ciências. Professora Adjunta. Universidade Federal de Juiz de Fora, Instituto de Ciências Exatas, Departamento de Química. Endereço: Rua José Lourenço Kelmer, s/n, Campus Universitário - Bairro São Pedro. Juiz de Fora/MG. CEP: 36036-900. Telefone: (32) 2102-3310 - R. 26. Email: andreia.afonso@ufjf.edu.br
} 
Los ejercicios de lectura y escritura son indispensables para la formación humana, ya que por medio de ellos, somos capaces de expresarnos y dialogar. Por lo tanto, es importante y necesario el desarrollo de prácticas de lectura y escritura en clases de educación secundaria de todas las asignaturas. En este contexto, este trabajo presenta una intervención didáctica en esta perspectiva, la de producción de diarios de científicos, por medio del ejercicio de la escritura creativa en grupos del segundo año de la educación secundaria en clase de Química. Por medio del estudio de los diarios de Análisis de Contenido, fue posible verificar posibles aproximaciones con las realidades vivenciadas por los estudiantes, una vez que fueron transferidas a los científicos, acciones, miedos y vivencias características tanto de la edad y del contexto social.

PALABRAS CLAVE: Escritura creativa. Realidades sociales. Enseñanza de Química.

\section{INTRODUÇÃO}

Muitos estudos da área de Educação têm se voltado às práticas de leitura e escrita durante o processo de escolarização, principalmente diante dos resultados dos exames oficiais, como o Programa Internacional de Avaliação dos Estudantes (PISA) e a Prova Brasil. O PISA se volta a questões que abordam três áreas do conhecimento - Leitura, Matemática e Ciências - enquanto na Prova Brasil, os testes são de Língua Portuguesa com foco na leitura, além da Matemática, cujos enunciados exigem nas suas respostas a resolução de problemas. Ambos os exames são aplicados aos discentes matriculados nos anos finais do Ensino Fundamental (oitavo e nono ano). Os resultados vêm apontando desempenho insatisfatório, com médias inferiores àquelas estipuladas como adequadas para o período escolar avaliado. Diante deles, podemos concluir que os estudantes leem pouco e, consequentemente, apresentam dificuldade ao redigir textos de diferentes gêneros ou, até mesmo, nas respostas solicitadas em avaliações escolares.

Além do PISA e da Prova Brasil, o Exame Nacional do Ensino Médio tem como uma de suas competências: "demonstrar domínio da modalidade escrita formal da Língua Portuguesa” (BRASIL, 2016, p. 13), sendo o exame um meio de garantir uma vaga em um curso de instituição de ensino superior.

Nesse sentido, a leitura e a escrita são essenciais, uma vez que nos permitem conhecer o mundo através das palavras. É por meio da leitura que adquirimos conhecimentos, enquanto por meio da escrita comunicamos ideias, expressamos opiniões e o conhecimento que possuímos. Atualmente, com o avanço da tecnologia, essas ações são mobilizadas a cada instante, já que as redes sociais são utilizadas cotidianamente.

Mas, nas escolas, muitas vezes, o desenvolvimento dessas competências fica somente sob a responsabilidade do professor de Língua Portuguesa, já que se acredita que as disciplinas da área de Linguagem é que devem se voltar a essas atividades. Nas demais disciplinas da matriz curricular se ensinam conceitos, mas não através da escrita que vai além dos relatórios científicos, mas com expressões matemáticas, com símbolos ou imagens, nos distanciando da leitura propriamente dita.

É importante, por exemplo, operar com algoritmos na Matemática ou na Física, mas o estudante precisa entender que, frente àquele algoritmo, está de posse de uma sentença da linguagem matemática, com seleção de léxico e com regras de 
articulação que geram uma significação e que, portanto, é a leitura e escrita da realidade ou de uma situação desta (BRASIL, 2000a, p. 16 e 17).

Ao mesmo tempo, "apresentações escritas e orais feitas pelos alunos também podem dar pistas ao professor de conceitos malformados, possíveis lacunas, e servir como instrumento de replanejamento de ações" (BRASIL, 2000b, p. 110).

Alguns dos fatores que contribuem para a crença de que a escrita deve ficar restrita às aulas de Língua Portuguesa são: a formação inicial dos professores de disciplinas que não pertencem à área de Linguagem, a grande quantidade de conteúdos que devem ser ministrados, a escassez de material didático e atividades nos livros didáticos que se voltem para a leitura e a escrita. Em relação à formação de professores, Flôr (2015) afirma que:

O fato de esses estudantes não terem hábitos e/ou não serem solicitados a escrever sobre suas ideias, pensamentos, impressões e críticas é muito comum nos cursos de Graduação em Ciências Naturais. Isso fortalece, em meu entendimento, a visão que muitos professores de ciências têm de que atividades que inclua ler e escrever só têm a ver com a disciplina de Língua Portuguesa, posto que em sua formação como professores essas não foram abordadas. Em ciências naturais - mesmo nas Licenciaturas - apaga-se ao máximo subjetividade e a oportunidade de produzir sentidos e se colocar no mundo (p. 39 e 40).

Assim, e considerando que "ler e escrever são tarefas da escola, questões para todas as áreas, uma vez que são habilidades indispensáveis para a formação de um estudante" (GUEDES; SOUZA, 2011, p. 19), entendemos ser importante a proposição de atividades que estejam relacionadas à leitura e escrita nas aulas de Química, proporcionando aos discentes a oportunidade do contato com diferentes gêneros textuais, que poderá promover a criatividade e a contextualização dos conteúdos abordados.

Na dimensão da prática de sala de aula, atividades escritas podem ser propostas nas aulas de Química como um dos caminhos possíveis para contextualizar o conteúdo, bem como para o desenvolvimento da linguagem, que por sua vez é inerente ao desenvolvimento do pensamento (GATTI et al., 2016, p. 142).

A contextualização nas aulas de Química auxilia a significar os conceitos através de fenômenos que são conhecidos, o que facilita a compreensão e nos permite uma aprendizagem que não aquela voltada à memorização de fórmulas, símbolos e estruturas. Ao unir leitura e contextualização, Ribeiro et al. (2017) advertem que:

A escolha de um texto para trabalhar em sala de aula é muito importante. Os alunos podem ter mais facilidade de atribuir uma significação à leitura quando situações do cotidiano são abordadas nos textos e a atividade não passa a ser simplesmente uma simulação de leitura (p. 160).

E assim como a contextualização, a História da Ciência auxilia na construção do conhecimento, à medida que "a partir da história e filosofia da ciência é possível construir um conhecimento realmente crítico dentro dos cursos de formação de professores e assim 
sucessivamente nas escolas de ensino básico" (MELO; ROCHA, 2017, p. 70). Por meio da História é possível termos uma visão de que a Ciência é feita por mulheres e homens que dedicaram um tempo de suas vidas aos estudos e obtiveram êxitos após diversas tentativas experimentais e/ou teóricas. Esse fato, muitas vezes, não está explícito nos livros didáticos, o que induz os alunos da Educação Básica a terem uma concepção de que a Ciência é imutável.

Teixeira, Greca e Freire Júnior (2009) destacam ainda outros objetivos da abordagem da História e Filosofia da Ciência nas aulas: melhor compreensão dos diferentes aspectos da natureza da ciência; aprimorar a atitude dos discentes em relação à ciência; motivar os alunos a participarem de debates, o que proporciona a elaboração de argumentos; e o desenvolvimento da metacognição, o que aumenta a capacidade de aprender.

E mais uma vez o ato de ler se faz fundamental, pois é através da leitura que se revela a História, uma vez que seu desenvolvimento está registrado nos livros e artigos científicos, e é somente a partir dos registros que a conhecemos. Aliás, Freire (1992) destaca outra importante relação entre a leitura da palavra e leitura de mundo.

\begin{abstract}
A leitura do mundo precede a leitura da palavra, daí que a posterior leitura desta não possa prescindir da continuidade da leitura daquele. Linguagem e realidade se prendem dinamicamente. A compreensão do texto a ser alcançada por sua leitura crítica implica a percepção das relações entre o texto e o contexto (p. 11-12).
\end{abstract}

Assim, aliar a História da Ciência com o ato de ler e escrever é uma proposta que pode contribuir significativamente para o ensino de Química, porém, poucas práticas docentes voltadas a essa metodologia são divulgadas. E por isso, este artigo tem por finalidade descrever um trabalho realizado no Ensino Médio, a partir da apresentação dos cientistas, buscando compreender a leitura de mundo desses discentes a partir da história de mulheres e homens que se dedicaram as pesquisas científicas, já que:

\footnotetext{
O texto, unidade complexa de significação, instaura um espaço de interlocução no qual intervém elementos contextuais e intertextuais, uma vez que é resultado de absorções e transformações de outros textos. A leitura, produção tão ativa quanto a produção textual, acontece ao dar ao texto nova vida, ao desencadear um processo criativo de compreensão e interpretação em face tio mundo exterior percebido e do mundo subjetivo de cada leitor (DELL'ISOLA, 1994, p.166).
}

Acreditamos que ao permitir que os alunos expressem seus sentimentos, a interação e o processo de ensino e aprendizagem podem ter resultados satisfatórios, já que conhecendo os problemas e dificuldades pelos quais passam, podemos buscar uma prática docente que esteja mais próxima a atender as demandas apresentadas.

\title{
O planejamento e a elaboração dos diários
}

A intervenção didática foi realizada no terceiro bimestre do ano de 2016, em uma escola da rede estadual, localizada em São Carlos/SP. A instituição escolar atende alunos do Ensino Fundamental e Médio nos períodos da manhã e da tarde. O Ensino Médio possui dez turmas, sendo três do primeiro ano, quatro do segundo e três do terceiro. Em média, estão 
matriculados trinta estudantes em cada uma das turmas. A prática descrita a seguir foi desenvolvida em três turmas do segundo ano do Ensino Médio.

Ela foi planejada a partir de observações a respeito da escrita dos discentes nas aulas de Química, uma vez que verificamos considerável dificuldade em responder a questões dissertativas, tanto em avaliações como em atividades diárias. Assim, buscando desenvolver a leitura e a escrita, propomos essa intervenção didática, buscando principalmente o exercício da escrita criativa em aulas de Química.

Inicialmente, pedimos aos discentes que formassem grupos de no máximo cinco integrantes, pois ao estarem discutindo sobre um determinado assunto, a cooperação e o respeito pela opinião do outro podem ser exercitados. A intervenção didática iniciou-se com a leitura de um trecho do "Diário da Dilma", uma sessão da revista Piauí que satiriza as situações cotidianas da ex-presidente da República, mesclando fatos reais e fictícios (REVISTA PIAUÍ, 2016). A escolha do texto se deu por ser uma leitura leve e criativa, de expressão informal e caráter subjetivo, além da presença de elementos afetivos e pessoais.

Após essa leitura, cada grupo formado recebeu uma cópia desse diário juntamente com a biografia de um renomado cientista (Marie Curie, Albert Einstein, Linus Pauling, Robert Bunsen e Svante Arrhenius). Por meio do diálogo, os discentes deveriam elaborar um diário de dez dias, como se fossem um desses cientistas - não necessariamente sequenciais, mas respeitando a cronologia do tempo - apresentando elementos reais da biografia e demais situações cotidianas, sem preocupação com julgamentos ou críticas. É importante que os discentes tenham contato com múltiplos tipos de textos para que possam construir aprendizagens linguísticas típicas do texto em questão (JOLIBERT; JACOB, 2006). A escrita foi realizada em duas aulas, perfazendo um total de cem minutos. Na aula seguinte, em plenária, os diários foram lidos pelos grupos e debatidos em sala, ressaltando os aspectos mais importantes sobre a Ciência, a Natureza da Ciência e a História da Ciência.

A atividade envolveu cinquenta e sete discentes de três turmas do segundo ano do Ensino Médio, que produziram dezesseis diários. Os diários foram estudados considerando os pressupostos da Análise do Conteúdo proposto por Franco (2008).

\section{As leituras e os elementos da realidade}

A Análise do Conteúdo consiste em um conjunto de técnicas com procedimentos sistemáticos que tem como ponto de partida a mensagem, por meio da qual por inferência, adquire um significado e um sentido. Primeiramente, tomamos como unidade de análise o tema, ou seja, uma asserção sobre determinado assunto, pois, por meio dessa unidade é possível obter um grande número de respostas permeadas por diferentes significados, representações sociais, opiniões, expectativas e conceitos.

A primeira etapa consistiu na pré-análise dos diários por meio da leitura flutuante, seguida da codificação dos dados e, por fim a categorização a priori, diferenciando e reagrupando as unidades de registro por semelhança.

Da leitura dos diários, podemos observar temas relacionados a sete elementos da vida cotidiana: relacionamentos, preconceito, drogas, criminalidade, ciências, sentimentos e saúde. As unidades destacadas permitem inferir que as situações vivências pelos cientistas nos diários podem - não na mesma medida - já terem sido vivenciadas pelos discentes, ou pertencerem a sua cultura e ao seu imaginário. 
O Quadro 1 apresenta as categorias criadas a partir da leitura dos diários e os elementos da realidade componentes de cada uma dessas categorias e no Quadro 2 o número de diários produzidos por cientistas. Em seguida, são apresentadas as unidades mais representativas de cada uma com as discussões pertinentes.

Quadro 1- Categorias e elementos da realidade.

\begin{tabular}{|l|l|}
\hline \multicolumn{1}{|c|}{ Categorias } & \multicolumn{1}{|c|}{ Elementos da realidade } \\
\hline Relacionamentos & $\begin{array}{l}\text { Descoberta do amor, desilusão amorosa, relações } \\
\text { familiares, amizades, influência dos amigos, } \\
\text { sexualidade, traições, desilusão amorosa, } \\
\text { erotismo, virgindade, identidade sexual, } \\
\text { prostituição, desejos, paixão, namoro, casamento. }\end{array}$ \\
\hline Preconceito & Gênero, deficiências intelectuais. \\
\hline Drogas & $\begin{array}{l}\text { Desenvolvimento de substâncias ilícitas, consumo } \\
\text { de drogas, consumo de álcool, descoberta, } \\
\text { utilização, tráfico. }\end{array}$ \\
\hline Criminalidade & $\begin{array}{l}\text { Planejamento de assalto, planejamento de roubo, } \\
\text { violência, condenação, prisão. }\end{array}$ \\
\hline Ciências & $\begin{array}{l}\text { Importância do conhecimento, descoberta de } \\
\text { substâncias, formação científica, prêmios. }\end{array}$ \\
\hline Sentimentos & $\begin{array}{l}\text { Reflexão sobre a vida, insatisfação pessoal, } \\
\text { tristeza, solidão, depressão, morte, saudade. }\end{array}$ \\
\hline Saúde & $\begin{array}{l}\text { Aquisição de doença, tratamento médico, doença } \\
\text { por trabalho com substâncias tóxicas. }\end{array}$ \\
\hline
\end{tabular}

Fonte: elaborado pelos autores.

Quadro 2 - Diários elaborados por cientistas.

\begin{tabular}{|c|c|c|c|c|c|}
\hline & Marie & Einstein & Pauling & Bunsen & Arrhenius \\
\hline Quantidade & 05 & 05 & 03 & 02 & 01 \\
\hline
\end{tabular}

Fonte: elaborado pelos autores.

\section{E vamos aos diários...}

Na turma 2A (vinte e seis alunos), foram elaborados nove diários, sendo dois sobre Marie, um sobre Einstein, três sobre Pauling, um sobre Bunsen e um sobre Arrhenius. Nos diários sobre Marie Curie, as categorias relacionamentos e preconceito se destacam, com quatro e três unidades, respectivamente. A seguir estão dois trechos que caracterizam essas categorias.

Hoje casei-me com meu grande amor. Afinal, será que ele é meu verdadeiro amor? Não sei se me dou os parabéns ou se me dou os pêsames (5 de novembro de 1895) Relacionamentos (2A-P01). 
Henri Becquerel me incentivou a estudar as irradiações. Falar é fácil, não é ele que vai ser hostilizado por ser uma mulher e fazer uma pesquisa só realizada por homens (2 de junho de 1986) - Preconceito (2A-P01).

No primeiro excerto, podemos identificar a dúvida em relação aos relacionamentos amorosos que são frequentes durante essa fase. Já no segundo, os estudantes trouxeram um fato que na época de Marie Curie era marcante: a falta de reconhecimento do trabalho da mulher nas pesquisas. Chassot (2004) declara que a Ciência ainda é predominantemente masculina e traz em seu trabalho um resgate histórico que nos ajuda entender as causas.

Sobre a quase ausência de mulheres na História da Ciência, não deixa de ser significativo que, ainda nas primeiras décadas do século XX, a Ciência estava culturalmente definida como uma carreira imprópria para a mulher, da mesma maneira que, ainda na segunda metade do século XX, se dizia quais eram as profissões de homens e quais as de mulheres (p. 13).

No diário sobre Einstein também a categoria relacionamentos foi a que teve mais unidades de registro. Vale destacar que esse diário foi redigido por dois alunos que se relacionam como namorados, o que justifica a predominância de elementos da vida de casal. Ao longo do texto é possível identificar em diferentes trechos a traição por parte da personagem feminina, a Mileva. Os autores também transportaram os acontecimentos para um período mais próximo ao atual, em que as redes sociais fazem parte do cotidiano.

Mileva saiu de manhã e ainda não voltou. Estou arrumando o quarto e encontrei o face dela aberto, lá estava a data e a hora do encontro com um tal de Bumsen, maldito cara safado (3 de dezembro de 2003) - Relacionamentos (2A-P02).

Nos três diários sobre Pauling, mais uma vez, o relacionamento é marcante. Entretanto, nesses textos o relacionamento é familiar, trazendo a morte do pai em muitos trechos da escrita e ainda, a morte da mãe e a morte de um filho.

Logo após 3 anos ela engravidou, foram 9 meses de muita alegria, más na hora do parto houve uma complicação nosso filho veio a falecer - Relacionamentos (2AP07).

Sobre Pauling se destacam também as categorias ciências e drogas. Em Ciências, Pauling reflete sobre a aprendizagem de conceitos químicos, fazendo uma analogia interessante a esse respeito. Podemos inferir que os autores podem ter experimentado uma sensação de "descoberta", interessando-se pela Química. Já em drogas, as unidades destacam o cientista como um criador de substâncias ilícitas, típico do senso comum, uma visão equivocada sobre o fazer Ciências.

O aprendizado da química é como uma criança indo para o banho, no princípio ela nega-se a ir, mas após um tempo ela aceita a entrar e depois não quer sair mais (20 de março) - Ciências (2A-P03). 
No laboratório criamos uma pílula que nos causa uma sensação de felicidade Drogas (2A-P09).

A visão distorcida sobre a Ciência e, até mesmo, do cientista, tem sido investigada por diferentes pesquisadores. De acordo Cachapuz et al (2011) é frequente a insistência de que o trabalho científico é reservado às minorias especialmente dotadas, o que é capaz de transmitir expectativas negativas para os alunos, com claras discriminações de natureza sexual e social. Goldschmidt et al. (2016) citam algumas dessas imagens distorcidas do fazer científico.

\begin{abstract}
Estas imagens traduzem-se em iconografias do cientista como homem da bata branca em um laboratório isolado, longe de fazer parte da sociedade, cheio de instrumentos e aparelhagens que poucos conhecem e sabem a utilidade, os quais o cientista manuseia para fazer experimentos e observações, em busca de "descobrir" algo (p. 176).
\end{abstract}

Os mesmos autores, com base no trabalho de Oliveira (2013) apontam as causas para essas concepções relacionadas a formação inicial dos professores que atuam na Educação Básica:

\begin{abstract}
Currículos que não se renovam, disciplinas específicas com professores sem formação adequada à área, ausência de experiência em laboratórios ou envolvimento com práticas relacionadas ao fazer Ciência, entre outros fatores, configuram-se como barreiras para uma formação de professores que considerem visões adequadas da Ciência (OLIVEIRA, 2013). Assim, a Ciência tem-se apresentado com diferentes visões dentro dos espaços educativos. Algumas destas representações estão incorporadas ao imaginário popular concernente à Ciência e se afastam da prática científica, bem como da forma como se constrói o conhecimento científico e tecnológico (p. 176).
\end{abstract}

Na escrita sobre Bunsen, a criminalidade foi a categoria mais marcante, com menção a assalto, prisão e mortes, como no trecho. Este diário foi elaborado por um único discente.

Já passou um ano e já estou no monte, roubei um banco em Las Vegas, consegui lucrar mais de um bilhão de dólares e duas barras de ouro - Criminalidade (2AP04).

Em relação a Arrhenius, as categorias relacionamento, criminalidade e drogas tiveram duas unidades de registro cada. Os relacionamentos, nesse diário se referem às más companhias, que levam a personagem a usar drogas e ao crime, destacando a influência das amizades na tomada de decisão e no comportamento próprio dos adolescentes.

Nos meus 13 anos, comecei a andar com maus elementos que sempre ficavão na porta da escola, comecei a matar aula só por brinkadeira - Relacionamentos (2AP08). 
Não sabia que isso poderia mecher no meu futuro mais isso não foi o pior em 1875 comecei a usar drogas se bem que só comecei a usar porque tava na moda-Drogas (2A-P08).

Os elementos presentes nos diários fazem parte do cotidiano dos discentes e foram transferidos aos cientistas em questão, uma vez que é comum espelhar em algo ou alguém aquilo que se vive e sente.

Na turma 2B (dezessete alunos) foram produzidos três diários: um sobre Marie, um sobre Einstein e um sobre Bunsen. No diário de Bunsen, destacam-se as categorias relacionamentos e sentimentos, respectivamente, com três e duas unidades.

Nunca perdi minha virgindade pois nunca me casei, permaneci casto morando com meus 20 gatos e 10 cachorros (29 de dezembro) - Relacionamentos (2B-P02).

Querido diário, a minha vida é um tédio, estou cansado de trabalhar e não ser reconhecido (20 de dezembro) - Sentimentos (2B-P02).

Em relacionamentos, encontra-se a desilusão amorosa, no qual se sugere que o cientista permaneceu sozinho durante sua vida, não conseguindo satisfazer-se intimamente, além do estereótipo de que toda pessoa solitária vive rodeada de animais. No que se refere aos sentimentos, é destacada a frustração pelo não reconhecimento dos feitos acadêmicos e ainda a depressão, supostamente adquirida pelo sofrimento amoroso. Essa percepção pode influenciar na escolha da carreira desses jovens, como aponta o estudo de Van Griethuijsen et al. (2015), no qual verificaram uma relação entre o interesse pela profissão científica com a visão de que se trata de um ofício realizado por pessoas criativas e que trabalham em equipe, contrapondo-se ao último trecho destacado de $\mathrm{P} 02$.

Chama atenção nesse diário, o preconceito para com pessoas com deficiência intelectual, presente em uma unidade, "abri um orfanato comecei a dar aula para crianças excepcionais, não que elas sejam, mas gosto de tratá-las assim” (2B-P02).

No diário sobre Einstein, elaborado por um grupo de meninos, estão presentes elementos próprios de sua realidade, em que todas as unidades identificadas são sobre relacionamentos, principalmente a amizade e relações fáceis:

Hoje encontrei um amigo que não vejo desde os meus 12 anos, depois de abandonar meus encontros judaicos. Mais tarde tem festas de ano novo, na praça com os parça (31 dezembro 1894) - Relacionamentos (2B-P01).

... depois eu fui ameaçado por ter ficado com uma menina lá que nem lembro quem era (01 janeiro 1895) - Relacionamentos (2B-P01).

Em contrapartida, no diário de Marie, aparecem principalmente os relacionamentos (quatro unidades) com o amor jovem e romântico, a desilusão amorosa que leva a prostituição e as drogas (uma unidade) como solução para os problemas, além os sentimentos (uma unidade) de insatisfação pessoal. O tom romântico do diário, marcado pelo amor jovem e o 
reencontro após anos e um futuro casamento, pode ser atribuído ao grupo, formado apenas por meninas.

Sofri minha primeira desilusão amorosa, para afogar minhas magoas, resolvi experimentar algo novo. Comecei a trabalhar no cabaré da esquina, onde me prostituia toda noite (7 novembro de 1878) - Relacionamentos (2B-P03).

Ao longo dos anos me aproximei mais de Albert nos apaixonamos e daqui a alguns minutos iremos nos casar (15 de dezembro de 1934) - Relacionamentos (2B-P03).

Suspeito que estou com uma doença na qual desconheço, estou ficando fraca e não sei para onde recorrer, por fim acabo me entregando as drogas (18 de março de 1913) - Saúde (2B-P03).

Assim como no diário de Einstein (2A-P02), nesse sugere-se que Marie Curie teve um relacionamento amoroso com outro cientista, embora ela tenha sido casada com Pierre Curie.

$\mathrm{Na}$ turma 2D (quatorze alunos), foram elaborados quatro diários: dois sobre Marie Curie e dois sobre Albert Einstein. Nos diários sobre Marie, as categorias relacionamentos, ciências e saúde possuem duas unidades cada, seguida por preconceito com uma unidade.

Hoje vi meu filho Bruno tendo relações amorosas com sua prima e que ele só tinha dito que era homossexual para me magoar, ele teve um filho com ela chamado Higor que era homossexual, aceitei ele, pois sempre sonhei ser vó (20/10/1895) Relacionamentos (2D-P02).

Hoje eu consegui realizar meu sonho e minha amiga também nós ganhamos o prêmio Nobel, este dia vai ser marcante para minha vida toda (10/10/1890) Ciências (2D-P02).

Estou numa situação complicada sabendo que estou doente e posso morrer, estou com uma doença grave (câncer) - Saúde (2D-P02).

No excerto destacado em relacionamentos, observa-se a questão de identidade sexual, em especial a homossexualidade, que no contexto não é tratado de forma preconceituosa, mas respeitosa. Cabe ressaltar que no grupo, um dos discentes utiliza o nome social, o que infere que por meio das vivências cotidianas em sala de aula, sobressai-se o respeito à pluralidade sexual em detrimento do preconceito.

Em ciências, o reconhecimento do trabalho por meio do recebimento do Nobel em conjunto com uma amiga, mostra a valorização da amizade e o trabalho coletivo em ciências. É de conhecimento que Marie recebeu seu prêmio Nobel de Física juntamente com outros cientistas, mas nenhuma mulher. Entretanto,

Essa cultura que exclui as mulheres do mundo cientifico também fica evidente pelas categorias dos prêmios, por meio de um levantamento sobre o prêmio Nobel, constatamos que 44 mulheres foram laureadas, num universo de 851 prêmios Nóbeles, ou seja, aproximadamente $5 \%$, sendo a categoria com mais premiações a da "paz", contando com 15 prêmios e o de "literatura" que conta com 12 mulheres premiadas, a categoria seguinte, com 10 prêmios conquistados é "medicina" seguido 
por "química" com quatro prêmios, "física" com dois prêmios e "economia" somente um (OGEDA; PEDRO; CHAGON, 2017, p. 222).

Nos diários de Einstein, todas as unidades são sobre relacionamentos, principalmente questões do imaginário sexual, a respeito de virgindade, descoberta sexual e relações fáceis.

Chegando lá fui abordado por uma garota loira, ela me disse que estava encantada com minha foto na praia na qual estava de shorts, sensualizando, e fomos para o quarto não pode ser dito o que aconteceu lá neste diário - Relacionamentos (2DP01).

São muitos os elementos da realidade e do imaginário dos alunos presentes nos diários dos cientistas, conforme destacado nas unidades apresentadas. Tem-se a predominância de elementos a respeito dos "Relacionamentos" (56 \%) de todos os tipos nos diários das três turmas analisadas. Esse destaque está de acordo com o caráter do gênero diário, uma vez que nele se expressam elementos afetivos e pessoais e ainda são próprios da adolescência, na qual se iniciam as primeiras relações e conflitos amorosos. Em segundo e terceiro, respectivamente, aparecem as "Drogas" (10\%) e a "Criminalidade" (9\%), sendo as drogas um recorrente na fala de adolescentes independente da região e estrato social (Quadro 3).

Tabela 1 - Frequência das categorias por turmas.

\begin{tabular}{|l|c|c|c|c|c|}
\hline & Turma 2A & Turma 2B & Turma 2C & Total & \% \\
\hline Relacionamentos & 21 & 10 & 8 & 39 & 56 \\
\hline Preconceito & 3 & 1 & 1 & 5 & 7 \\
\hline Drogas & 6 & 1 & 0 & 7 & 10 \\
\hline Criminalidade & 6 & 0 & 0 & 6 & 9 \\
\hline Ciências & 2 & 1 & 2 & 5 & 7 \\
\hline Sentimentos & 1 & 3 & 0 & 4 & 6 \\
\hline Saúde & 2 & 0 & 2 & 4 & 6 \\
\hline
\end{tabular}

Fonte: elaborado pelos autores.

Entretanto, chama atenção a criminalidade, principalmente pelas unidades destacarem o planejamento de roubos e assaltos, o que é preocupante, pois se entendemos como uma expressão da realidade, infere-se que esses jovens vivem em um contexto em que a criminalidade está presente e faz parte do seu cotidiano, pois o bairro no qual localiza-se a escola é na região periférica da cidade.

Em relação aos cientistas, a Tabela 2 ilustra a frequência com que cada categoria aparece nos diários dos cientistas. Notadamente, "Relacionamentos" é o mais frequente e a única que está presente no diário de todos os cientistas. Cada cientista tem em seu diário, ao menos, elementos de no mínimo três categorias. Marie Curie destaca-se por possuir praticamente todos os elementos, exceto criminalidade e, destaca-se pelo preconceito, conforme discutido anteriormente em relação ao seu trabalho como uma das pioneiras na ciência moderna. 
Tabela 2 - Frequência das categorias por cientista.

\begin{tabular}{|l|c|c|c|c|c|c|}
\hline & Einstein & & Marie & Pauling & Bunsen & Arrhenius \\
\hline Relacionamentos & 14 & & 10 & 8 & 5 & 2 \\
\hline Preconceito & 0 & & 4 & 0 & 1 & 0 \\
\hline Drogas & 1 & & 1 & 3 & 0 & 2 \\
\hline Criminalidade & 0 & & 0 & 1 & 3 & 2 \\
\hline Ciências & 0 & & 2 & 2 & 1 & 0 \\
\hline Sentimentos & 0 & & 1 & 0 & 3 & 0 \\
\hline Saúde & 1 & & 3 & 0 & 0 & 0 \\
\hline
\end{tabular}

Fonte: elaborado pelos autores.

\section{A escrita criativa e os elementos da realidade predominantes}

A intervenção didática ocorreu por meio da escrita de um diário. A respeito dos diários, os discentes apresentaram dificuldade em compreender sua estrutura, demonstrando falta de familiaridade com o gênero textual, além da presença de graves erros de ortografia e concordância verbal e nominal. Assim, é importante que não apenas a disciplina de Língua Portuguesa exercite a escrita, mas todas as áreas, uma vez que conforme destacado por Guedes e Souza (2011) com os quais concordamos, é uma habilidade que deve ser desenvolvida em todas as disciplinas.

Apesar de pouca familiaridade com o gênero e do pouco estímulo a escrita criativa, os alunos exercitaram satisfatoriamente a criatividade e a imaginação, não ficando presos a reprodução das informações dos textos, pois dos dezesseis diários, apenas um restringiu-se a mera reprodução. Nessa perspectiva, também endossamos a necessidade do desenvolvimento de um maior número de intervenções nessa linha de pensamento, do desenvolvimento da criatividade.

Assim, a partir do conhecimento do que pensam e sentem os alunos, poderemos planejar e propor aulas que atendam e contemplem as necessidades da turma, de modo a alcançarmos os objetivos propostos para o processo de ensino e aprendizagem e, portanto, a uma educação de mais qualidade.

\section{REFERÊNCIAS}

BRASIL. Ministério da Educação. Parâmetros Curriculares Nacionais - Ensino Médio. Brasília, 2000a. 109p.

BRASIL. Ministério da Educação. Orientações Educacionais Complementares aos Parâmetros Curriculares Nacionais - Ciências da Natureza, Matemática e suas Tecnologias. Brasília, 2000b. 144p.

BRASIL. Ministério da Educação. Instituto Nacional de Estudos e Pesquisas Educacionais Anísio Teixeira. Redação no ENEM 2016 - Cartilha do participante. Brasília, 2016. 60p. 
CACHAPUZ, A. et al. A necessária renovação do ensino das ciências. São Paulo: Cortez, 2005.

CHASSOT, A. A Ciência é masculina? É, sim senhora!... Contexto \& Educação, ano 19, n.71/72, p. 9-28, 2004.

DELL'ISOLA, R. L. P. A interação sujeito-linguagem em leitura. Ensaios de Semiótica, n. 2830, p. 163-170, 1994.

DIÁRIO DA DILMA: em tempo de crise, ovo de codorna é caviar. Revista Piauí, São Paulo, mar. 2016. Disponível em: <http://piaui.folha.uol.com.br/materia/em-tempo-de-crise-ovo-decodorna-e-caviar/>. Acesso em: 16 out. 2017.

FLÔR, C. C. Na busca de ler para ser em aulas de química. Ijuí: Editora Unijuí, 2015.

FRANCO, M. L. P. B. Análise do conteúdo. Brasília: Liber Livro Editora, 2008.

FREIRE, P. A importância do ato de ler: em três artigos que se completam. São Paulo: Cortez, 1992.

GATTI, I. M. C. et al. Escrita e criatividade na contextualização da Química. In.: Revista percursos, v. 17, n. 35, p.140-159, 2016.

GUEDES, P. C.; SOUZA, J. M. Leitura e escrita são tarefas da escola e não só do professor de português. In: NEVES, I. C. B. (Org.). Ler e escrever: compromisso de todas as áreas. Porto Alegre: UFRGS, 2011. p.19-24.

GOLSCHMIDT, A. I. et al. O que é Ciência? Concepções de Licenciandos em Ciências Biológicas e Química. Contexto \& Educação, ano 31, n. 99, p. 173-200, 2016.

JOLIBERT, J.; JACOB, J. Além dos muros da escola: a escrita como ponte entre os alunos e comunidade. Porto Alegre: Artmed, 2006.

MELO, A. P.; ROCHA, D. C. Reflexões sobre a importância da História e Filosofia da Ciência no Ensino de Ciências. In.: Revista Espaço Acadêmico, n. 192, p. 69-77, 2017. 
OGEDA, C. M. M.; PEDRO, K. M.; CHACON, M. C. M. Gênero e superdotação: um olhar para a representação feminina. In.: Revista Educação e Linguagens, v. 6, n. 10, p. 217-231, 2017.

RIBEIRO, R. A. et al. O uso da leitura para ensinar o conteúdo de fenômenos no ensino médio. In.: Revista de Ciências de Ensino de Ciências e Matemática, v. 8, n. 1, p. 155-165, 2017.

TEIXEIRA, E. S.; GRECA, I. M.; FREIRE JR., O. The history and philososophy in physics teaching: a research synthesis of didatic intervention. In.: Science \& Education, v. 21, n. 6, p. 771-796, 2009.

VAN GRIETHUIJSEN, R. A. L. F. et al. Global Patterns in Students' Views of Science and Interest in Science. In.: Research in Science Education, v. 45, n. 4, p. 581-603, 2015.

Recebido em: 17/06/2017

Aprovado em: 15/07/2017 